Ambiente \& Água - An Interdisciplinary Journal of Applied Science
ISSN 1980-993X - doi:10.4136/1980-993X
www.ambi-agua.net
E-mail: ambi-agua@agro.unitau.br

\title{
Índices de Qualidade da Água e de Estado Trófico na Represa Dr. João Penido (Juiz de Fora, MG)
}

\author{
doi: 10.4136/ambi-agua.1290
}

Received: 28 Jan. 2014; Accepted: 27 Feb. 2014

\author{
Magaly H. S. Bucci; Luiz Fernando C. de Oliveira* \\ Universidade Federal de Juiz de Fora (UFJF) - Juiz de Fora, MG, Brasil \\ *Autor correspondente: e-mail: luiz.oliveira@ufjf.edu.br, \\ magalybucci@gmail.com
}

\section{RESUMO}

A represa Dr. João Penido contém o reservatório que é a principal fonte de abastecimento de água potável da cidade de Juiz de Fora, localizada na região sudeste do Brasil. Sua construção se deu em 1934 e desde então, vem sofrendo com o mau uso e ocupação das terras em seu entorno. O objetivo geral deste estudo foi caracterizar a qualidade hídrica do manancial, relacionando os resultados com o uso e ocupação do solo da bacia hidrográfica. Para isto foram realizadas análises físico-químicas e microbiológicas de amostras de água referente aos seguintes parâmetros: temperatura da água, oxigênio dissolvido, $\mathrm{pH}$, turbidez, sólidos totais, demanda bioquímica de oxigênio, nitrato, fósforo total, clorofila $a$ e coliformes termotolerantes. Os resultados obtidos foram comparados com a Resolução 357/2005 do Conselho Nacional de Meio Ambiente (CONAMA) e aqueles que apresentaram desconformidade com a norma foram: oxigênio dissolvido, $\mathrm{pH}$, turbidez, fósforo total e demanda bioquímica de oxigênio. Foi calculado o Índice de Qualidade da Água (IQA) e o Índice de Estado Trófico (IET) para as amostras analisadas. Os resultados mostraram a predominância do estado "mesotrófico" e nível "médio" de qualidade da água, indicando que as formas de uso e ocupação do solo da bacia hidrográfica têm produzido impactos negativos no ecossistema aquático. O monitoramento demonstrou ser ferramenta fundamental, proporcionando subsídios para a elaboração de um plano de gestão integrada nas ações que envolvem a preservação e recuperação da qualidade do manancial.

Palavras-chave: estado trófico, manancial, monitoramento, plano de gestão integrada, qualidade da água.

\section{Water Quality and Trophic State indices at the Dr. João Penido Dam (Juiz de Fora, MG, Brazil)}

\section{ABSTRACT}

The Dr. João Penido Dam contains the reservoir that is the main source of drinking water for the city of Juiz de Fora, located in the southeastern region of Brazil. It was built in in 1934 and has since suffered from the misuse and occupation of the land that surrounds it. This study sought to characterize the reservoir's water quality and to correlate our results with land use. Accordingly, we performed physical-chemical and microbiological analyses of water samples in order to measure the following parameters: water temperature, dissolved oxygen, 
$\mathrm{pH}$, turbidity, total solids, biochemical oxygen demand, nitrate, total phosphorus, chlorophyll $a$ and thermo-tolerant coliform. The results were compared with Resolution 357/2005 of the National Environmental Council (CONAMA), and it was found that the dissolved oxygen, $\mathrm{pH}$, turbity, total phosphorus and biochemical oxygen demand were not in conformity. We also calculated the Water Quality Index (WQI) and Trophic State Index (TSI) for the all of the samples and found the water to be in a predominately "mesothrophic" state and the water quality level to be "medium." This suggests that occupation and the forms of use of the watershed have negatively impacted the aquatic ecosystem. Monitoring has proven itself to be a critical tool, providing subsidies for the development of an integrated management plan for the preservation and restoration of the quality of the reservoir.

Keywords: trophic state, water source, monitoring, integrated management plan, water quality index.

\section{INTRODUÇÃO}

O constante crescimento da demanda de água implica na necessidade de aumentar a disponibilidade deste recurso para atender os seus múltiplos usos. Como consequência, a construção de barragens para diversas finalidades representa o progresso. Em contraposição, acarreta uma série de impactos nos ecossistemas naturais decorrentes da transformação de ambientes lóticos em lênticos, provocando alterações no comportamento natural e na qualidade hídrica dos rios e córregos represados (Von Sperling, 1999), sendo uma interferência antropogênica de grande impacto ecológico nos ecossistemas. Pimenta et al. (2012) citam que alguns exemplos destas alterações são: diminuição do fluxo de água, aumento da taxa de sedimentação, aumento do tempo de residência da água, estratificação térmica e diminuição das concentrações de oxigênio dissolvido, dentre outros.

Embora o uso mais nobre que se possa dar a um recurso hídrico seja o consumo humano, os mananciais brasileiros têm apresentado progressiva degradação da qualidade de suas águas (Carneiro et al., 2005). Contribuem para isso o lançamento inadequado de efluentes (sanitários e industriais), o uso de fertilizantes, agrotóxicos e pesticidas em áreas agrícolas (Carmo et al., 2005; Carvalho et al., 2000; Dores e De-Lamonica-Freire, 2001), além do mau uso e ocupação das terras, dentre outras. Além disso, os múltiplos usos de reservatórios no Brasil, aliado às atividades humanas tem acelerado também o processo de eutrofização dos corpos hídricos (Soares et al., 2008). Desta forma, a preocupação com a degradação destes ambientes aquáticos tem crescido no meio científico, sendo necessário incrementar os estudos e ampliar os conhecimentos sobre o assunto.

Outra questão relevante é que existe uma carência de informações a respeito de pequenas bacias hidrográficas, como é o caso da bacia da represa Dr. João Penido, situada do município de Juiz de Fora (Minas Gerais). Não há estudos sistematizados sobre a qualidade das águas do manancial, sendo que o mesmo era desconhecido para a comunidade científica até a realização desta pesquisa.

O reservatório foi construído em 1934 e desde então, vem sofrendo processos de degradação, apesar de estar protegido por leis municipais, estaduais e federais. Este fato pode ser evidenciado pelas ocupações irregulares às margens dos corpos d'água, erosões, ausência de mata ciliar, assoreamento, bem como a proliferação de macrófitas aquáticas em vários pontos do manancial, principalmente nas regiões de entrada dos tributários, indicando possível estado de eutrofização. Este fato vem causando grande preocupação, uma vez que o manancial é responsável por $65 \%$ do abastecimento público de água potável da cidade (Juiz de Fora, 2004).

Tendo em vista a sua importância e o cenário atual em que se encontra, este trabalho foi estruturado apresentando como objetivo principal a caracterização da qualidade hídrica do manancial, relacionando os resultados com o uso e ocupação do solo da bacia hidrográfica. 
Para isso foram delineados três objetivos específicos: (1) realização de análises físicoquímicas e microbiológicas de amostras de água; (2) comparação dos resultados obtidos com os limites definidos pela Resolução 357/2005 do Conselho Nacional de Meio Ambiente (CONAMA) (Brasil, 2005), utilizando como referência "águas doces classe 1"; (3) cálculo do Índice de Qualidade da Água (IQA) e do Índice de Estado Trófico (IET) mensal para as águas da represa e de dois principais tributários.

Pode-se avaliar a qualidade hídrica de um reservatório utilizando-se o Índice de Qualidade da Água (IQA). Seu cálculo é baseado em nove parâmetros (descritos em material e métodos), que possuem pesos diferenciados de acordo com sua importância relativa no cálculo do índice. Estes parâmetros representam os indicadores de qualidade da água e foram estabelecidos pela National Sanitation Foudantion nos Estados Unidos, para o desenvolvimento de um índice que demostrasse a qualidade da água. O IQA reflete a interferência por esgotos sanitários e outros materiais orgânicos, nutrientes e sólidos presentes na água (Minas Gerais, 2005).

Outra forma de investigação é pelos Índices de Estado Trófico, que foram desenvolvidos para avaliar a qualidade da água quanto ao enriquecimento por nutrientes e seu efeito relacionado ao crescimento excessivo de algas ou macrófitas, facilitando a classificação de corpos d'água em diferentes graus de trofia. Eles podem auxiliar nas decisões sobre riscos de ocorrer florações de algas, bem como no controle da eutrofização (aumento na concentração de nutrientes na água, especialmente fósforo e nitrogênio), que tem sido uma preocupação mundial para os tomadores de decisões referentes ao gerenciamento de recursos hídricos (Brito et al., 2011; Cunha et al., 2013; Liu et al., 2014).

Vários países do mundo vêm enfrentando o desafio da eutrofização acelerada e a degradação dos ambientes aquáticos provocados principalmente pelas interferências humanas. Nos reservatórios brasileiros o problema tem aumentado, tornando os ambientes mais vulneráveis, afetando o balanço ecológico (Rangel et al., 2012), e comprometendo a qualidade das águas no país (Brito et al., 2011).

Com base nos conhecimentos científicos adquiridos e aqui apresentados, poderá ser elaborado um plano de gerenciamento integrado para a preservação dos recursos hídricos da região, além de proporcionar estudos comparativos para reservatórios de abastecimento de água no Brasil e no mundo.

\section{MATERIAL E MÉTODOS}

\section{1.Área de estudo}

Juiz de Fora se localiza no estado de Minas Gerais, na região sudeste do Brasil. O município está inserido na Bacia Hidrográfica do Rio Paraíba do Sul, uma das mais populosas do país. O clima da região, de acordo com a classificação de Köppen, é do tipo Cwa, ou seja, mesotérmico com verões quentes e úmidos. O município está enquadrado na região fitoecológica denominada Floresta Estacional Semidecidual (formação do Bioma Mata Atlântica), típica de climas com duas estações bem definidas (Juiz de Fora, 2004).

Os córregos estudados, denominados córrego Grama e ribeirão dos Burros, bem como a represa Dr. João Penido estão contidos na sub-bacia (SB) do ribeirão dos Burros, pertencente à bacia do rio Paraibuna (Juiz de Fora, 2004). De acordo com a Deliberação Normativa 16/1996 do Conselho Estadual de Política Ambiental (COPAM) (Minas Gerais, 1996), que dispõe sobre o enquadramento dos corpos d'água da bacia do rio Paraibuna, as águas desta SB no trecho estudado, são classe 1.

A área da bacia hidrográfica da represa é de $68 \mathrm{~km}^{2}$. Trata-se de um sistema raso, com profundidade média de 6,53 metros e máxima, de 10,90 metros, cuja área superficial é 370 hectares (valores aproximados) (CESAMA, 2010). A vazão regularizada do reservatório é 
$750 \mathrm{~L} / \mathrm{s}$ e o volume de água armazenada é aproximadamente $14.094 .000 \mathrm{~m}^{3}$ (dado de 1985) (Leme Engenharia S. A., 1985). Atualmente, este volume é bem menor, em função das consequências advindas do próprio represamento, como proliferação de plantas aquáticas, diminuição da vazão dos cursos d'água e os processos de sedimentação que o reservatório vem sofrendo, desde que foi construído. Esta situação é mais evidente na região de entrada dos tributários. As características de degradação citadas para a represa também fazem parte da realidade dos afluentes. A ausência de mata ciliar e áreas florestadas, além do mau uso e ocupação das terras da região são outras características importantes que devem ser consideradas para os ambientes estudados.

Foram definidos cinco pontos de coleta, sendo dois nos tributários citados, e três na represa, cuja localização pode ser visualizada na Figura 1. Os pontos de amostragem dos afluentes localizam-se à montante de sua foz na represa.

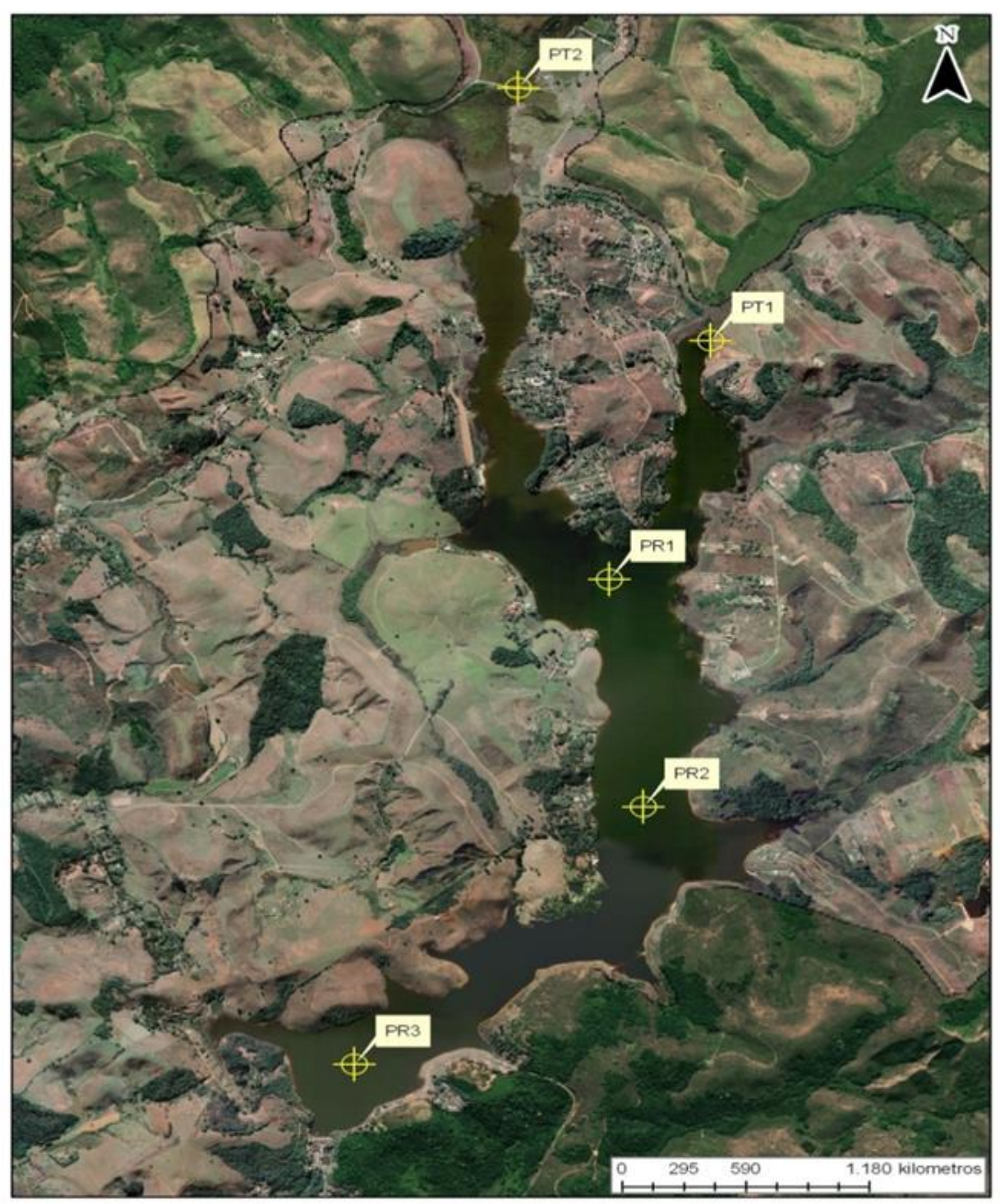

Figura 1. Ortofoto do vôo aerofotogramétrico, datada de 2007, indicando os pontos de coleta em tributários e represa: PT1: córrego Grama; PT2: ribeirão dos Burros; PR1: Ponto 1 da represa (zona fluvial); PR2: Ponto 2 da represa (zona intermediária); PR3: Ponto 3 da represa (zona lacustre).

Fonte: Juiz de Fora (2007). 
A localização, altitude e profundidade média dos pontos de coleta estão apresentados na Tabela 1.

Tabela 1. Localização, altitude e profundidade média dos pontos de coleta.

\begin{tabular}{c|cccc}
\hline Ponto & \multicolumn{2}{|c}{ Coordenadas geográficas UTM } & $\begin{array}{c}\text { Altitude } \\
(\mathrm{m})\end{array}$ & $\begin{array}{c}\text { Profundidade média } \\
(\mathrm{m})\end{array}$ \\
\hline PT1 & $21^{\circ} 38^{\prime} 29,8^{\prime \prime} \mathrm{S}$ & $43^{\circ} 23^{\prime} 09,1^{\prime \prime} \mathrm{W}$ & 754,0 & 0,97 \\
PT2 & $21^{\circ} 37^{\prime} 40,9^{\prime \prime} \mathrm{S}$ & $43^{\circ} 23^{\prime} 43,2^{\prime \prime} \mathrm{W}$ & 752,8 & 0,97 \\
PR1 & $21^{\circ} 39^{\prime} 25,6^{\prime \prime} \mathrm{S}$ & $43^{\circ} 23^{\prime} 24,3^{\prime \prime} \mathrm{W}$ & 752,7 & 5,39 \\
PR2 & $21^{\circ} 40^{\prime} 17,9^{\prime \prime} \mathrm{S}$ & $43^{\circ} 23^{\prime} 23,7^{\prime \prime} \mathrm{W}$ & 751,9 & 6,71 \\
PR3 & $21^{\circ} 40^{\prime} 51,8^{\prime \prime} \mathrm{S}$ & $43^{\circ} 24^{\prime} 07,5^{\prime \prime} \mathrm{W}$ & 745,5 & 8,87 \\
\hline
\end{tabular}

\subsection{Metodologia}

Foram realizadas campanhas mensais durante um ano (período de julho/ 2009 a junho/2010). As técnicas de coleta e amostragem seguiram a NBR 9898 da Associação Brasileira de Normas e Técnicas (ABNT) (ABNT, 1987). As amostras foram coletadas aproximadamente a $10 \mathrm{~cm}$ da superfície, em frascos de polietileno de $500 \mathrm{~mL}$, previamente ambientados com a água do local por três vezes. Em seguida, foram preservadas em isopor com gelo (temperatura em torno de $4^{\circ} \mathrm{C}$ ) até a chegada aos laboratórios.

Os parâmetros analisados foram: temperatura da água, oxigênio dissolvido (OD), pH (medidos in situ com auxílio de equipamentos portáteis), turbidez, sólidos totais, demanda bioquímica de oxigênio (DBO), nitrato $\left(\mathrm{NO}_{3}{ }^{-}\right)$, fósforo total (PT), clorofila $a$ e coliformes termotolerantes. Os respectivos métodos de ensaio seguiram o preconizado no Standard Methods for the Examination of Water and Wastewater (APHA, 1998).

O IET foi calculado no período de julho/ 2009 a junho/ 2010, de acordo com a metodologia proposta por Lamparelli (2004), que foi uma adaptação para ambientes tropicais do índice adotado por Carlson (1977), utilizado para climas temperados. Esse método também é utilizado pela Companhia de Saneamento do Estado de São Paulo (CETESB) na rede de monitoramento do referido estado. As Equações de cálculo estão apresentadas a seguir:

Ambientes lóticos (córregos/rios): Equações 1 e 2

$$
\begin{aligned}
& \operatorname{IET}(\mathrm{CL})=10 \times\left(6-\left\{\frac{-0,7-0,6 \times \ln [\mathrm{CL}]}{\ln 2}\right\}\right)-20 \\
& \operatorname{IET}(\mathrm{PT})=10 \times\left(6-\left\{\frac{0,42-0,36 \times \ln [\mathrm{PT}]}{\ln 2}\right\}\right)-20
\end{aligned}
$$

Ambientes lênticos (reservatórios): Equações 3 e 4

$$
\operatorname{IET}(\mathrm{CL})=10 \times\left(6-\left\{\frac{0,92-0,34 \times \ln [\mathrm{CL}]}{\ln 2}\right\}\right)
$$




$$
\operatorname{IET}(\mathrm{PT})=10 \times\left(6-\left\{\frac{1,77-0,42 \times \ln [\mathrm{PT}]}{\ln 2}\right\}\right)
$$

em que:

PT: concentração de fósforo total em $\mu \mathrm{g} / \mathrm{L} ; \mathrm{CL}$ : concentração de clorofila $a \mathrm{em} \mu \mathrm{g} / \mathrm{L} ; \ln$ : logaritmo natural.

O resultado final do IET corresponde à média aritmética simples dos índices relativos ao fósforo total e a clorofila $a$, conforme Equação 5:

$$
\mathrm{IET}=\frac{\mathrm{IET}(\mathrm{CL})+\mathrm{IET}(\mathrm{PT})}{2}
$$

As Equações 1, 2 e 5 foram utilizadas para os pontos dos córregos (PT1 e PT2) e as Equações 3, 4 e 5, para os pontos da represa (PR1, PR2 e PR3).

Os limites dos diferentes níveis tróficos para rios e reservatórios são: ultraoligotrófico (IET $\leq 47)$; oligotrófico $(47<$ IET $\leq 52)$; mesotrófico $(52<$ IET $\leq 59)$; eutrófico $(59<$ IET $\leq 63)$; supereutrófico $(63<$ IET $\leq 67)$; hipereutrófico (IET > 67) (Lamparelli, 2004).

IQA foi calculado no período de dezembro/ 2009 a junho/ 2010, de acordo com a metodologia utilizada pelo Instituto Mineiro de Gestão das Águas (IGAM), no Projeto "Águas de Minas", referente ao monitoramento das águas superficiais do estado de Minas Gerais. O IQA corresponde a um número que varia de 0 a 100, cujo cálculo é baseado em nove parâmetros, com pesos diferenciados: $\mathrm{OD}$, coliformes termotolerantes, $\mathrm{pH}, \mathrm{NO}_{3}^{-}, \mathrm{PT}$, DBO, temperatura da água, turbidez e sólidos totais. O IQA é calculado pelo produtório ponderado das qualidades de água correspondentes aos nove parâmetros, conforme Equação 6, de acordo com a fórmula (Minas Gerais, 2005):

$$
I Q A=\prod_{i=1}^{9} q_{i}^{{ }^{w_{i}}}
$$

em que:

IQA = Índice de Qualidade de Água;

$\mathrm{q}_{\mathrm{i}}=$ qualidade do parâmetro i obtido pela curva média específica de qualidade;

$\mathrm{W}_{\mathrm{i}}=$ peso atribuído ao parâmetro, em função de sua importância na qualidade, entre 0 e 1 .

As equações obtidas para o Sistema de Cálculo de Qualidade da Água, bem como as curvas médias de qualidade dos nove parâmetros individuais estão apresentadas em Minas Gerais (2005).

Os níveis de qualidade da água e suas respectivas faixas são: excelente $(90<\mathrm{IQA} \leq 100)$; bom $(70<\mathrm{IQA} \leq 90)$; médio $(50<\mathrm{IQA} \leq 70)$; ruim $(25<\mathrm{IQA} \leq 50)$; muito ruim $(0 \leq \mathrm{IQA} \leq 25)$ (Minas Gerais, 2005). 


\section{RESULTADOS E DISCUSSÃO}

Os resultados dos parâmetros, a estatística descritiva dos mesmos, bem como os limites definidos pela Resolução CONAMA 357/2005 para corpos d'água classe 1, estão apresentados na Tabela 2.

Tabela 2. Resultados obtidos e estatística descritiva dos parâmetros analisados para os pontos amostrados em tributários e represa, incluindo os limites definidos pelo CONAMA para "águas doces classe 1".

\begin{tabular}{|c|c|c|c|c|c|c|c|}
\hline \multirow{2}{*}{ Parâmetro } & \multirow{2}{*}{ Resultado } & \multicolumn{2}{|c|}{ Pontos dos tributários } & \multicolumn{3}{|c|}{ Pontos da represa } & \multirow{2}{*}{$\begin{array}{c}\text { Limites } \\
\text { CONAMA } \\
\text { 357/2005 } \\
\end{array}$} \\
\hline & & PT1 & PT2 & PR1 & PR2 & PR3 & \\
\hline \multirow{3}{*}{$\mathrm{T}\left({ }^{\circ} \mathrm{C}\right)$} & $\mathrm{M} \pm \mathrm{DP}$ & $22,73 \pm 4,31$ & $21,92 \pm 4,53$ & $24,03 \pm 3,48$ & $24,23 \pm 3,34$ & $24,15 \pm 3,34$ & \multirow{3}{*}{ - } \\
\hline & Máx. & 34,00 & 30,30 & 31,60 & 31,40 & 30,30 & \\
\hline & Mín. & 17,00 & 16,00 & 19,20 & 19,80 & 18,50 & \\
\hline \multirow{3}{*}{$\begin{array}{c}\mathrm{OD}\left(\mathrm{mg} \cdot \mathrm{L}^{-}\right. \\
\left.{ }^{\prime}\right)\end{array}$} & $\mathrm{M} \pm \mathrm{DP}$ & $5,81 \pm 1,40$ & $5,19 \pm 1,46$ & $6,35 \pm 0,71$ & $6,32 \pm 0,85$ & $6,52 \pm 1,09$ & \multirow{3}{*}{$\begin{array}{l}>6,0 \\
\operatorname{mg} . \mathrm{L}^{-1}\end{array}$} \\
\hline & Máx. & 7,50 & 7,90 & 7,50 & 7,50 & 8,40 & \\
\hline & Mín. & 4,00 & 3,00 & 5,10 & 5,10 & 5,10 & \\
\hline \multirow{3}{*}{$\mathrm{pH}$} & $\mathrm{M} \pm \mathrm{DP}$ & $6,38 \pm 0,58$ & $5,95 \pm 0,64$ & $6,73 \pm 0,70$ & $6,79 \pm 0,67$ & $6,82 \pm 0,77$ & \multirow{3}{*}{$\begin{array}{c}\text { Entre } 6,0 \mathrm{e} \\
9,0\end{array}$} \\
\hline & Máx. & 7,60 & 7,30 & 8,00 & 7,70 & 7,60 & \\
\hline & Mín. & 5,00 & 5,00 & 5,60 & 5,70 & 5,20 & \\
\hline \multirow{3}{*}{$\begin{array}{l}\text { Turbidez } \\
\text { (UNT) }\end{array}$} & $\mathrm{M} \pm \mathrm{DP}$ & $26,64 \pm 32,65$ & $52,70 \pm 51,52$ & $20,64 \pm 14,32$ & $\begin{array}{c}18,34 \pm 17,01 \\
17,01\end{array}$ & $17,74 \pm 16,33$ & \multirow{3}{*}{ 40,0 UNT } \\
\hline & Máx. & 115,00 & 126,70 & 40,60 & 41,80 & 40,80 & \\
\hline & Mín. & 1,00 & 2,26 & 2,96 & 1,00 & 1,00 & \\
\hline \multirow{3}{*}{$\begin{array}{l}\text { Sólidos } \\
\text { totais } \\
\left(\mathrm{mg} \cdot \mathrm{L}^{-1}\right)\end{array}$} & $\mathrm{M} \pm \mathrm{DP}$ & $32,29 \pm 45,44$ & $36,86 \pm 63,23$ & $37,86 \pm 36,35$ & $25,43 \pm 24,42$ & $41,57 \pm 52,28$ & \multirow{3}{*}{$\begin{array}{l}500,0 \\
\mathrm{mg} . \mathrm{L}^{-1}\end{array}$} \\
\hline & Máx. & 135,00 & 180,00 & 120,00 & 80,00 & 160,00 & \\
\hline & Mín. & 10,00 & 10,00 & 20,00 & 10,00 & 19,00 & \\
\hline \multirow{3}{*}{$\begin{array}{c}\mathrm{DBO} \\
\left(\mathrm{mg} \cdot \mathrm{L}^{-1}\right)\end{array}$} & $\mathrm{M} \pm \mathrm{DP}$ & $11,47 \pm 3,55$ & $8,87 \pm 3,17$ & $10,76 \pm 2,06$ & $6,90 \pm 3,56$ & $9,83 \pm 2,74$ & \multirow{3}{*}{$3,0 \mathrm{mg} \cdot \mathrm{L}^{-1}$} \\
\hline & Máx. & 16,21 & 14,73 & 13,67 & 14,50 & 13,50 & \\
\hline & Mín. & 5,71 & 4,11 & 7,60 & 2,70 & 4,32 & \\
\hline \multirow{3}{*}{$\begin{array}{l}\text { Nitrato } \\
\left(\mathrm{mg} \cdot \mathrm{L}^{-1}\right)\end{array}$} & $\mathrm{M} \pm \mathrm{DP}$ & $0,554 \pm 0,261$ & $0,442 \pm 0,382$ & $0,561 \pm 0,360$ & $0,486 \pm 0,323$ & $0,467 \pm 0,294$ & \multirow{3}{*}{$10,0 \mathrm{mg} \cdot \mathrm{L}^{-1}$} \\
\hline & Máx. & 0,919 & 1,143 & 1,015 & 0,906 & 0,859 & \\
\hline & Mín. & 0,222 & 0,059 & 0,126 & 0,190 & 0,194 & \\
\hline \multirow{3}{*}{$\begin{array}{c}\mathrm{PT} \\
\left(\mathrm{mg} \cdot \mathrm{L}^{-1}\right)\end{array}$} & $\mathrm{M} \pm \mathrm{DP}$ & $0,082 \pm 0,129$ & $0,074 \pm 0,126$ & $0,066 \pm 0,114$ & $0,066 \pm 0,100$ & $0,068 \pm 0,116$ & \multirow{3}{*}{$*$} \\
\hline & Máx. & 0,470 & 0,460 & 0,420 & 0,360 & 0,420 & \\
\hline & Mín. & 0,009 & 0,013 & 0,007 & 0,006 & 0,004 & \\
\hline \multirow{3}{*}{$\begin{array}{c}\text { Clorofila } a \\
\left(\mu \mathrm{g} \cdot \mathrm{L}^{-1}\right)\end{array}$} & $\mathrm{M} \pm \mathrm{DP}$ & $2,53 \pm 0,68$ & $1,71 \pm 0,79$ & $3,35 \pm 0,88$ & $3,14 \pm 0,87$ & $3,18 \pm 0,55$ & \multirow{3}{*}{$10 \mu \mathrm{g} . \mathrm{L}^{-1}$} \\
\hline & Máx. & 3,75 & 2,85 & 5,00 & 4,85 & 4,05 & \\
\hline & Mín. & 1,75 & 0,30 & 2,35 & 2,05 & 2,35 & \\
\hline
\end{tabular}

Nota: *Ambiente lêntico: 0,020 mg. $\mathrm{L}^{-1}$; tributários diretos de ambientes lênticos: 0,025 mg. $\mathrm{L}^{-1}$.

Média \pm M \pm DP = Média \pm Desvio Padrão; Máx. = valor máximo; Mín. = valor mínimo. 
O parâmetro coliformes termotolerantes foi determinado em Número Mais Provável por $100 \mathrm{ml}$ (NMP/100 mL). O método utilizado (APHA, 1998; Silva et al., 2005) não permitiu a quantificação exata na maioria das análises laboratoriais realizadas, mas observou-se que sua presença na água é baixa. Por este motivo, não foi apresentada estatística descritiva dos mesmos. Os resultados estão apresentados na Tabela 3.

Tabela 3. Resultados de coliformes termotolerantes (NMP/100 mL) em águas de tributários e represa.

\begin{tabular}{c|cc|ccc}
\hline \multirow{2}{*}{ Mês } & \multicolumn{2}{|c|}{ Pontos dos tributários } & \multicolumn{3}{c}{ Pontos da represa } \\
\cline { 2 - 6 } & PT1 & PT2 & PR1 & PR2 & PR3 \\
\hline dez/09 & $<3$ & $<3$ & $<3$ & $<3$ & $<3$ \\
jan/10 & $<3$ & $<3$ & $<3$ & $<3$ & $<3$ \\
fev/10 & $<3$ & $<3$ & $<3$ & $<3$ & $<3$ \\
mar/10 & $<3$ & $<3$ & $<3$ & $<3$ & $<3$ \\
abr/10 & $<3$ & $<3$ & $<3$ & $<3$ & $<3$ \\
mai/10 & $<3$ & $<3$ & $<3$ & $<3$ & $<3$ \\
jun/10 & $<3$ & 4 & $<3$ & $<3$ & 4 \\
\hline
\end{tabular}

As porcentagens de resultados em desacordo com a Resolução CONAMA 357/2005 estão apresentadas na figura 2. Os demais parâmetros, quando contemplados por esta norma estiveram de acordo com os limites estabelecidos.

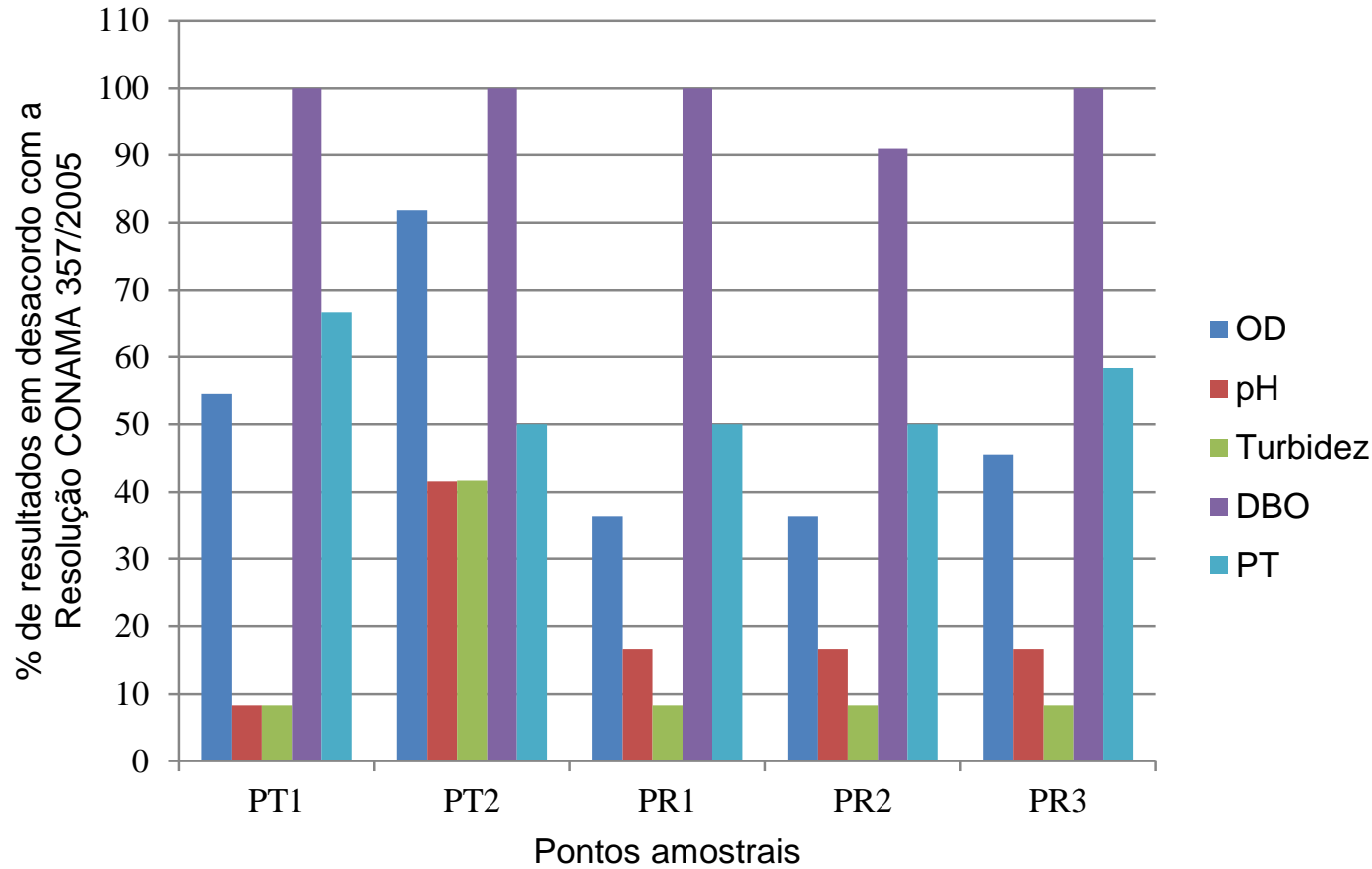

Figura 2. Porcentagens de resultados dos parâmetros analisados em desconformidade com os limites definidos pela Resolução CONAMA 357/2005 nos pontos amostrais estudados. 


\subsection{Tratamento estatístico dos dados de IQA e IET}

O teste estatístico aplicado para os resultados dos dois pontos nos córregos (PT1 e PT2) foi o teste t de Student, que compara somente duas médias. A análise de variância ANOVA é uma extensão do teste t de Student (Vieira, 2006) e foi utilizada para os pontos da represa (PR1, PR2 e PR3), pois permite a comparação de qualquer número de médias. A ideia é comparar a variação da eficiência entre tratamentos ao longo do tempo de operação, por meio de um teste estatístico, associado aos graus de liberdade, a um nível de significância de 5\%. As análises estatísticas foram realizadas com o auxílio do software Primer of Biostatistics versão 4.0 (Stanton, 1997).

\subsection{Resultados dos parâmetros individuais}

\subsection{Oxigênio dissolvido (OD)}

A represa apresentou melhores índices de OD que os afluentes, fato também observado na rede de monitoramento das águas superficiais do estado de São Paulo (Lamparelli, 2004).

As menores médias obtidas nos pontos dos tributários podem indicar entradas de carga orgânica provenientes de efluentes domésticos e/ou escoamento superficial da bacia de drenagem. Acredita-se também que as macrófitas interferem nesses resultados, pois são abundantes nessas regiões. Essas plantas fornecem oxigênio para o meio aquático, porém, após completarem seu ciclo de vida entram em processo de decomposição, passando a ser consumidoras de OD da massa líquida. Além disso, elas constituem barreiras físicas e podem aumentar a resistência à livre movimentação de água e ar, bem como diminuir a ação dos ventos sobre o espelho d'água. As macrófitas também possibilitam maior retenção de material orgânico transportado de locais à montante da bacia hidrográfica, que ao ser degradado pelos microrganismos aeróbios, proporcionam consumo de OD. A proliferação de plantas aquáticas é consequência do incremento de nutrientes no meio, bem como de interferências antrópicas que começam a surgir a partir do próprio represamento.

A menor média de todos os pontos e a maior porcentagem de resultados em desconformidade com a Resolução CONAMA 357/2005 ocorreram no ribeirão dos Burros (PT2). Para este afluente, além do OD que teve 75,0 \% do total de resultados em desacordo, outros parâmetros também não atenderam a referida norma, como: PT $(50,0 \%)$, pH $(41,6 \%)$, turbidez $(41,6 \%)$ e DBO $(100,0 \%)$. Isso indica grande impacto neste ambiente, proporcionado pelo mau uso e ocupação das terras em seu entorno. Uma das justificativas está na rede de esgotos clandestina construída pelos moradores do local, direcionando os efluentes domésticos para o ribeirão, à montante do ponto de coleta (PT2). As reações de degradação da matéria orgânica presente nestes resíduos consomem OD do meio. Os resultados mostram a interferência antrópica provocando deterioração do ecossistema aquático, que fica mais vulnerável devido à ausência de mata ciliar.

As concentrações mínimas observadas no reservatório ocorreram no período de estiagem (maio a julho/2010) devido a menor diluição de matéria orgânica e outras substâncias na água. Nos afluentes, as mínimas ocorreram em mês de cheia (dezembro/2009) devido ao escoamento superficial da bacia de drenagem, mostrando que os córregos são mais vulneráveis ao impacto das águas pluviais.

\subsection{Potencial Hidrogeniônico (pH)}

Normalmente o $\mathrm{pH}$ de águas doces é mantido em torno da neutralidade, pelo sistema de tamponamento baseado nas concentrações de carbonato e bicarbonato em solução provenientes do $\mathrm{CO}_{2}$. As florações de algas ou macrófitas no ambiente interferem nesse sistema tampão, podendo-se observar aumento de acidez ou alcalinidade da água. Se há aumento da fotossíntese, o $\mathrm{pH}$ tende a aumentar, pois há consumo de $\mathrm{CO}_{2}$ no processo. Porém, os íons carbonato ou bicarbonato existentes no meio o tampona, mantendo o $\mathrm{pH}$ em 
torno de 6,5. Por outro lado, os organismos heterotróficos tendem a baixar o $\mathrm{pH}$ da massa líquida por meio dos processos metabólicos de respiração e decomposição, que liberam $\mathrm{CO}_{2}$ no meio (Fernandes et al., 2005). Estes últimos processos também contribuem com o incremento de outras substâncias no ambiente, como os ácidos húmicos e fúlvicos (CETESB, 2010).

$\mathrm{Na}$ análise dos resultados, observou-se que a variação sazonal foi bastante significativa. No período de estiagem, todas as medições estiveram em conformidade com os limites definidos pelo CONAMA.

A intensa pluviosidade ocorrida em dezembro/2009 $(315,6 \mathrm{~mm})$ registrada pela Estação Pluviométrica da Represa Dr. João Penido (EPRJP), provocou stress nos ambientes. Entre dezembro/ 2009 e abril/ 2010 (cheia), o ribeirão dos Burros (PT2) apresentou pH em desconformidade em todas as medições, sendo obtidos valores que variaram de 5,0 a 5,9. Águas de chuva podem interferir no $\mathrm{pH}$ dos ecossistemas aquáticos continentais, pois normalmente são ácidas, com pH entre 5,0 e 6,0 (Esteves, 1998). O efeito é mais acentuado, quando os ambientes possuem baixa capacidade de tamponamento e isso foi observado para este ribeirão no referido período, onde todas as amostras estiveram em desconformidade, retornando ao equilíbrio somente em maio/2010. Este ponto de coleta localiza-se entre as plantas e provavelmente isso está interferindo no sistema tampão do ecossistema aquático. Os efeitos são potencializados pela disposição inadequada de esgotos no córrego. Observou-se que a represa e o córrego Grama (PT1) demonstraram melhor capacidade de recuperação do equilíbrio iônico do sistema, após o stress provocado pelo aumento da pluviosidade.

A menor média obtida e a maior porcentagem de medições referentes ao $\mathrm{pH}$ em desacordo com o CONAMA foram obtidas para o ribeirão dos Burros (PT2) pelos motivos já explanados. Para o reservatório, a menor média foi obtida no PR1 por sofrer forte influência das águas tributárias.

\subsection{Turbidez}

As médias relativas a este parâmetro foram maiores nos tributários, se comparadas ao reservatório, fato também constatado na rede de monitoramento do estado de São Paulo (Lamparelli, 2004).

As maiores médias, bem como a maior porcentagem de resultados de turbidez em desacordo com o CONAMA foram obtidas no ribeirão dos Burros (PT2), justificado pelas características lóticas deste ambiente, abundância de plantas aquáticas e pela presença de esgotos no córrego. Foi feita uma observação referente à interferência antrópica neste ribeirão, nas coletas de dezembro/ 2009 e janeiro/ 2010. As macrófitas haviam sido arrancadas ou cortadas e deixadas na água por moradores do local, à montante do ponto de coleta. Foram observados na análise das amostras, respectivamente, em dezembro/2009 e janeiro/2010: menores valores de OD e $\mathrm{pH}$, e maiores valores para a turbidez do que os outros pontos de coleta. A retirada das plantas provocou revolvimento e ressuspensão de sedimentos do fundo, alterando na qualidade da água do ribeirão. Nos meses seguintes à ocorrência, no período de fevereiro a maio/2010, foram observados os maiores valores obtidos para a turbidez no PT2 (em desacordo com o CONAMA), fazendo uma análise temporal no período observado. Em fevereiro e março/2010, também houve incremento de $\mathrm{PT}_{\text {e }} \mathrm{NO}_{3}{ }^{-}$. Acredita-se que os nutrientes do meio aquático que tinham sido absorvidos pelas plantas foram sendo disponibilizados para a água, porque as mesmas foram deixadas no local. Estas observações indicam que a capacidade das macrófitas funcionarem como um filtro para o manancial ficou prejudicada.

Para a represa, as maiores médias de turbidez foram obtidas no PR1, justificado por localizar-se em uma região de grande mistura da zona fluvial (Thornton, 1990; Soares et al., 2008). Os valores máximos obtidos para a turbidez nos três pontos do reservatório ocorreram 
em abril/2010. Levando-se em conta que a represa é um ambiente raso, fatores como correntes de vento que revolvem os sedimentos do fundo podem ter sido a causa do processo (Ford, 1990). Os valores máximos para a turbidez obtidos nos afluentes ocorreram no período de cheia. Considerando que os valores máximos para o reservatório ocorreram no período de estiagem, pode-se inferir que a pluviosidade interfere mais na turbidez dos afluentes, que são ambientes mais frágeis e vulneráveis do que o reservatório. O grande desvio padrão observado para todos os pontos demonstra a grande variação sazonal para este parâmetro.

Nos sistemas estudados, os valores de turbidez variaram de 1,00 a 126,70 UNT. Estes ambientes são desprovidos de mata ciliar e áreas florestadas em quase toda a sua extensão, consequência do mau uso das terras da região. Estes valores encontrados são considerados altos, se comparados com águas de bacias hidrográficas recobertas por floresta de Mata Atlântica, que são da ordem de 0,15 a 4,9 UNT (Silva et al., 2009). Isso mostra a importância da presença e manutenção de cobertura vegetal na preservação dos corpos hídricos, pois funcionam como um filtro para a água.

\subsection{Sólidos totais}

Todos os resultados obtidos neste estudo atenderam aos limites definidos pelo CONAMA. Os máximos para todos os pontos foram registrados em dezembro/2009, fato associado à alta pluviosidade deste mês. Na represa, foi constatado à montante dos pontos PR1 e PR3, obras de terraplanagem com movimentação de terra, provocando assoreamento na margem direita em novembro e dezembro/2009. Neste último mês, as máximas concentrações de sólidos totais podem estar relacionadas aos altos valores para a DBO, além de baixos índices para OD e pH, obtidos para a mesma amostra nos dois pontos amostrais. Além disso, no mesmo período citado, ocorreu à montante do PR1 queima de vegetação na margem direita, que deixou o solo exposto, agravando a situação na zona fluvial. As intensas chuvas de dezembro/2009 potencializaram os efeitos das interferências antrópicas observadas no entorno do manancial para os dois pontos citados.

A maior média de todos os pontos foi observada no PR3. Isso demonstra que a região próxima à barragem da represa é receptora de sedimentos provenientes de processos erosivos das margens à montante, bem como do escoamento superficial de toda a bacia de drenagem. Este ponto deveria apresentar menores concentrações de sólidos totais, uma vez que está próximo à zona lacustre.

\subsection{Demanda Bioquímica de Oxigênio (DBO)}

Todos os resultados estão em desacordo com o CONAMA, exceto no mês de janeiro para o PR2, onde foi obtido o valor mínimo de $2,70 \mathrm{mg} . \mathrm{L}^{-1}$.

O valor máximo registrado ocorreu no córrego Grama (PT1), em abril/2010. As intensas chuvas de março $(320,6 \mathrm{~mm}$, de acordo com a EPRJP) provocaram o revolvimento e ressuspensão de sedimentos acumulados em toda a área brejosa coberta por macrófitas na margem direita e à montante do ponto de coleta, bem como o aumento do volume da água do córrego. O transporte foi facilitado pelo maior fluxo, incrementando o teor de carga orgânica na água. Este afluente também apresentou a maior média e a justificativa está na vulnerabilidade deste ambiente ao escoamento superficial. Sua margem esquerda possui um pequeno talude que frequentemente sofre capina e remoção de vegetação ciliar, pelos moradores do entorno, fato que compromete a qualidade hídrica deste córrego. As características lênticas proporcionadas pela proliferação de macrófitas em sua margem direita, também favorecem o acúmulo de nutrientes e carga orgânica na água.

$\mathrm{Na}$ represa, em janeiro/ 2010 foram observadas erosões na margem direita da represa, à montante do PR3. As alterações na qualidade da água foram percebidas, fato que causa preocupação por estar próximo à Estação de Tratamento de Água (ETA). Além da 
concentração máxima de DBO para este ponto, também houve valores em desacordo o CONAMA para o $\mathrm{pH}$, OD e PT na mesma amostra.

\subsection{Nitrato $\left(\mathrm{NO}_{3}{ }^{-}\right)$}

Neste estudo, todos os resultados referentes a este parâmetro estiveram em conformidade com os limites estabelecidos pelo CONAMA.

A máxima concentração para o $\mathrm{NO}_{3}^{-}$no PR1 em março/2010, coincidiu com valores acima da média para este ponto em relação aos seguintes parâmetros: turbidez, DBO e PT. O fato pode estar relacionado ao assoreamento proveniente de movimentações de terra provocado por moradores do local, fato observado em vários pontos da margem direita, à montante do PR1, indicando o aporte de materiais presentes no solo para a represa. $\mathrm{O}$ maior índice pluviométrico do período também foi registrado neste mês, o que agravou a situação.

\subsection{Fósforo total (PT)}

Neste estudo, os picos de PT observados em julho/ 2009 nos cinco pontos amostrais ocorreram após um período de seca, seguido de chuvas ocorridas anteriormente ao dia da coleta. As fontes difusas de poluição contribuíram para esta ocorrência, agravando a situação. Este fato também foi observado por Haddad (2007) no monitoramento do rio São Miguel (Minas Gerais, Brasil).

A concentração máxima e a maior porcentagem de resultados em desacordo com o CONAMA ocorreram no PT1, justificado pelas características lênticas deste ambiente. Na represa, a máxima se deu no PR1, o que era de se esperar, por estar próximo à zona fluvial.

Porém, fato que chamou a atenção foi que, apesar da pouca diferença, a maior média dos pontos da represa e a maior porcentagem de resultados em desacordo com o CONAMA foram obtidas no PR3. Isso indica que a zona lacustre está sendo impactada por fontes de fósforo. Estas regiões, geralmente são pobres em relação a este nutriente (Kimmel et al., 1990; Pagioro et al., 2005 e Soares et al., 2008), porém, isso não foi observado para a represa Dr. João Penido. Conforme já foi comentado, esta zona da represa é região receptora de sedimentos, e como eles transportam fósforo, ocorre o incremento deste parâmetro na água.

As médias dos afluentes foram maiores, se comparadas ao reservatório, fato também observado por Lamparelli (2004) na rede de monitoramento do estado de São Paulo.

\subsection{Clorofila $a$}

Todos os resultados obtidos atenderam aos limites do CONAMA. Pagioro et al. (2005) citam que existe uma relação positiva entre a clorofila $a$ e o PT, indicando que ele estimula a biomassa fitoplanctônica. Esta abordagem foi evidenciada neste estudo, pelos picos registrados para o PT em todos os pontos em julho/ 2009, coincidindo com as concentrações máximas para a clorofila $a$ no PT1, PR2 e PR3. O PR1 teve concentração de clorofila $a$ próxima à máxima obtida para esta mesma amostra. Nesse mês, somente para o PT2, a relação entre os parâmetros foi inversa, sendo obtida a mínima da clorofila $a$ na mesma amostra em que foi registrada a máxima para o PT. Vários fatores influenciam a produtividade do fitoplâncton, além da disponibilidade de nutrientes. Fatores físicos, como a velocidade da água, e as consequentes taxas de sedimentação, influenciam a transparência da água e a turbulência do ambiente (Lamparelli, 2004; Soares et al., 2008). O maior fluxo de água neste ponto amostral do ribeirão dos Burros pode explicar esta relação inversa ocorrida em julho para os parâmetros PT e clorofila $a$.

A represa apresentou as maiores médias, se comparada aos córregos, fato comum de acontecer e que também foi observado por Lamparelli (2004) nos corpos d'água do estado de São Paulo. Por ser ambiente lêntico, o reservatório proporciona maior incidência de luz e acúmulo de nutrientes, favorecendo o incremento da concentração de clorofila $a$. 
A maior média dos córregos ocorreu no PT1, justificada pelas características lênticas deste afluente. A maior média da represa ocorreu no PR1, demonstrando maior tendência à eutrofização deste ponto, inclusive por estar mais próximo da entrada dos tributários.

Em junho/ 2010, o córrego Grama (PT1) apresentou muita terra exposta proveniente de capina e remoção da vegetação ciliar em sua margem esquerda. Acredita-se que este fato está relacionado aos resultados encontrados nas amostras analisadas, que indicaram valor mínimo para a clorofila $a$, bem como valores acima da média para a turbidez e resultados de OD, PT e DBO em desacordo com o CONAMA.

\subsection{Coliformes termotolerantes}

As bactérias do grupo coliformes são consideradas as principais indicadoras de contaminação fecal (CETESB, 2010). Foi verificado que todas as amostras apresentaram resultados bem inferiores aos limites definidos pelo CONAMA, sendo todas consideradas "próprias" e de "excelente" qualidade, em relação a este parâmetro.

\subsection{2. Índice de Qualidade da Água (IQA)}

Os Índices de Qualidade da Água (IQA) se baseiam principalmente em fatores limnológicos e físico-químicos (Carvalho et al., 2000). Com base nos resultados do IQA, foi feita uma análise espacial por ponto amostrado, avaliando-se e caracterizando-se a qualidade da água de cada um.

Com relação ao parâmetro coliformes termotolerantes, onde os valores não foram determinados exatamente $(<3,0)$, foi utilizado o valor 3,0 para os cálculos do IQA. Este procedimento também é adotado pelo IGAM no monitoramento das águas superficiais de Minas Gerais.

O IQA excelente não foi observado em nenhum ponto. Esta condição vem sendo observada no desenvolvimento do projeto "Águas de Minas" desde 1997, na maioria dos corpos d'água monitorados pelo IGAM (2010) no estado de Minas Gerais.

Os resultados de IQA, bem como a estatística descritiva, estão demonstrados na Tabela 4.

Tabela 4. Resultados de IQA e porcentagens obtidas para cada classificação de qualidade da água nos pontos amostrais estudados.

\begin{tabular}{cc|ccc|ccc}
\hline \multirow{2}{*}{ Pontos } & & $\begin{array}{c}\text { Variação } \\
\text { do IQA }\end{array}$ & $\begin{array}{c}\text { Média } \\
\text { IQA }\end{array}$ & $\begin{array}{c}\text { Desvio } \\
\text { Padrão }\end{array}$ & \multicolumn{2}{c}{ Qualidade da Água (IQA) } \\
\cline { 6 - 8 } & & & & & Ruim & Médio & Bom \\
\hline \multirow{2}{*}{ Tributários } & PT1 & 61,6 a 72,5 & 65,7 & 4,2 & - & $85,7 \%$ & $14,3 \%$ \\
& PT2 & 47,0 a 72,9 & 58,9 & 10,0 & $28,6 \%$ & $57,1 \%$ & $14,3 \%$ \\
\hline \multirow{2}{*}{ Represa } & PR1 & 63,6 a 72,2 & 68,1 & 2,9 & - & $71,4 \%$ & $28,6 \%$ \\
& PR2 & 70,8 a 79,0 & 74,9 & 3,2 & - & - & $100,0 \%$ \\
& PR3 & 61,6 a 75,2 & 68,9 & 4,5 & - & $71,4 \%$ & $28,6 \%$ \\
\hline
\end{tabular}

\subsection{Análise dos tributários}

Em uma análise mais ampla, o nível de qualidade da água dos afluentes variou de "ruim" a "bom", com predominância do "médio".

$\mathrm{O}$ teste $\mathrm{t}$ de Student aplicado revelou que $\mathrm{P}>0,05(\mathrm{P}=0,127)$, ou seja, não existe diferença significativa entre os pontos estudados, a um nível de confiança de $95 \%$. 
No córrego Grama (PT1), houve predominância do IQA médio. Levando-se em conta os pesos de cada parâmetro, a influência maior na deve-se aos altos valores de DBO e PT observados. O nível "bom" foi obtido em janeiro/2010 e os parâmetros que influenciaram neste resultado foram os bons índices de OD e pH observados. Este córrego apresentou maior média do IQA em relação ao ribeirão dos Burros.

No ribeirão dos Burros (PT2), houve predominância do IQA médio devido aos baixos valores de OD e $\mathrm{pH}$, além de altos valores para a DBO. Em fevereiro e março/2010 a qualidade foi "ruim", justificado pelos altos valores para o PT, além dos parâmetros já citados acima. Em janeiro, a qualidade da água foi "boa", sendo que os parâmetros de maior influência foram os baixos teores de $\mathrm{NO}_{3}{ }^{-}$e PT.

\subsection{Análise do reservatório}

De uma maneira geral, o nível de qualidade da água da represa variou de "médio" a "bom".

Ao aplicar a análise de variância ANOVA, verificou-se que $\mathrm{P}<0,05(\mathrm{P}=0,004)$, revelando diferença significativa entre os pontos. O ponto PR2 difere estatisticamente dos pontos PR1 e PR3, e isto pode ser observado também pelos valores das médias.

$\mathrm{O}$ ponto $\mathrm{PR} 1$, próximo à zona fluvial apresentou predominância do IQA médio no período de cheia (dezembro/ 2009 a abril/2010). Os parâmetros que não atenderam à Resolução CONAMA 357/2005 neste período como DBO, pH e PT influenciaram neste resultado. A água esteve com IQA bom nos meses de estiagem (maio e junho/ 2010). Neste período, o pH da água foi próximo à neutralidade e a temperatura da água foi menor.

O IQA no período estudado foi bom em 100,00 \% do total de amostras analisadas no ponto PR2, próximo à zona intermediária. Os parâmetros de maior peso que contribuíram positivamente para esses resultados foram: bons índices de $\mathrm{OD}$ e valores de $\mathrm{pH}$ próximos à neutralidade, bem como menores valores de DBO. Acredita-se que a melhor qualidade das águas neste ponto (se comparada com PR1 e PR3), se deve também às margens preservadas na direção e à montante do PR2. A margem direita, apesar das ocupações, possui mata densa e preservada. A margem esquerda não possui ocupações e não apresentou sinais de erosões. Apesar da ausência de mata ciliar nesta margem, a cobertura do solo com gramíneas ofereceu proteção, dificultando o carreamento de sedimentos para a água. Este ponto apresentou a maior média, indicando melhor qualidade da água.

O ponto PR3 apresentou comportamento semelhante ao PR1, havendo predominância do IQA médio, observado no período de cheia (dezembro/ 2009 a abril/ 2010). As médias praticamente iguais dos dois pontos, também revelam esta similaridade. Os parâmetros que tiveram maior peso nestes resultados foram altos valores de DBO e maiores temperaturas da água. O nível foi bom nos meses de estiagem (maio e junho/ 2010). Contribuíram positivamente para esse resultado, os valores de $\mathrm{pH}$ mais próximos à neutralidade e menores valores de DBO e temperatura da água.

Este ponto localizado na zona lacustre deveria apresentar águas de melhor qualidade, porém isso não foi observado. Foi identificado que esta região próxima à barragem sofre influência de processos erosivos que ocorrem à montante da represa, principalmente na margem direita entre o PR2 e o PR3.

\subsection{5. Índice de Estado Trófico (IET)}

Carlson (1977) afirma que o IET não equivale a um índice de qualidade de água. O termo qualidade está mais relacionado aos seus usos múltiplos e implica em um julgamento que deve ser separado do estado trófico.

Os resultados de IET, bem como a estatística descritiva, estão demonstrados na Tabela 5. 
Tabela 5. Resultados de IET e porcentagens obtidas para cada estado trófico nos pontos amostrais estudados.

\begin{tabular}{|c|c|c|c|c|c|c|c|c|}
\hline \multirow{2}{*}{ Ponto } & & \multirow{2}{*}{$\begin{array}{l}\text { Variação do } \\
\text { IET }\end{array}$} & \multirow{2}{*}{$\begin{array}{l}\text { Média } \\
\text { IET }\end{array}$} & \multirow{2}{*}{$\begin{array}{l}\text { Desvio } \\
\text { Padrão }\end{array}$} & \multicolumn{4}{|c|}{ Estado Trófico (IET) } \\
\hline & & & & & Super-eutrófico & Eutrófico & Mesotrófico & Oligotrófico \\
\hline \multirow{3}{*}{ Tributários } & PT1 & 50,9 a 63,7 & 55,6 & 3,3 & $8,3 \%$ & - & $83,3 \%$ & $8,3 \%$ \\
\hline & & & & & & & & \\
\hline & PT2 & 48,4 a 57,6 & 53,0 & 3,1 & - & - & $75,0 \%$ & $25,0 \%$ \\
\hline \multirow{3}{*}{ Represa } & PR1 & 50,3 a 62,6 & 53,9 & 3,5 & - & $8,3 \%$ & $50,0 \%$ & $41,6 \%$ \\
\hline & PR2 & 48,5 a 62,3 & 53,7 & 3,9 & - & $8,3 \%$ & $58,3 \%$ & $33,3 \%$ \\
\hline & PR3 & 48,2 a 62,3 & 53,6 & 3,9 & - & $8,3 \%$ & $58,3 \%$ & $33,3 \%$ \\
\hline
\end{tabular}

\subsection{Análise dos tributários}

Aplicando-se o teste t de Student para os córregos, encontrou-se $\mathrm{P}>0,05(\mathrm{P}=0,063)$. Isso mostra que estatisticamente, não existe diferença significativa entre os pontos, com um nível de confiabilidade de $95 \%$.

No córrego Grama (PT1), o fluxo de água é bem mais lento. Este fato favorece maiores concentrações de PT e clorofila $a$, indicando maior tendência à eutrofização e consequentemente explica a maior média para o IET encontrada para este ponto, em relação ao ribeirão dos Burros. O PT1 apresentou predominância do estado "mesotrófico" durante o período observado. Em julho/ 2009, a classificação foi "supereutrófico", justificado pelo pico observado para o PT em todos os pontos, além do valor de clorofila $a$ acima da média para este ponto, na mesma amostra. Houve apenas uma ocorrência para o estado "oligotrófico" neste ponto amostral, de um total de doze amostras analisadas.

O ribeirão dos Burros (PT2) também apresentou estado "mesotrófico" predominante. Apesar da infestação de macrófitas impedir o curso normal do córrego, há maior fluxo de água no ponto de coleta. Isso influenciou nos baixos índices de clorofila $a$ obtidos, permitindo menor média para o IET em relação ao córrego Grama. Do total analisado, houve três ocorrências para o estado "oligotrófico" neste ponto.

\subsection{Análise do reservatório}

O teste estatístico ANOVA aplicado revelou que $\mathrm{P}>0,05(\mathrm{P}=0,853)$, não existindo diferença significativa entre os 3 pontos, com um nível de confiança de $95 \%$.

Em uma primeira análise, o grau de trofia da represa variou de "oligotrófico" a "eutrófico". Porém, observou-se predominância do estado "mesotrófico", indicando produtividade intermediária, com possíveis implicações sobre a qualidade e o uso da água.

Observou-se que as médias do IET foram praticamente iguais nos três pontos da represa. Portanto, a tendência geral de apresentar características eutróficas na parte alta do reservatório, e oligotróficas na zona próxima à barragem (Lamparelli, 2004; Kimmel et al., 1990; Pagioro et al., 2005) não foi observada na represa Dr. João Penido.

As tendências maiores de eutrofização puderam ser evidenciadas no mês de julho/2009, demonstrando alta produtividade do ecossistema em relação às suas condições naturais. Os picos de PT observados neste mês, aliados aos valores de clorofila $a$ acima da média para todos os pontos do reservatório, justificaram a classificação "eutrófico" verificada para os três pontos amostrais neste mês. 


\section{CONCLUSÕES}

- O uso e ocupação do solo na área da bacia da represa Dr. João Penido não têm sido adequadas para que o manancial seja utilizado para abastecimento público de Juiz de Fora, evidenciando deterioração da qualidade de suas águas.

- As principais interferências antrópicas identificadas, que possivelmente provocaram alterações na qualidade da água devido à ocupação ilegal no entorno do manancial, foram: movimentos de terra às margens da represa, remoção inadequada de macrófitas, lançamento inadequado de efluentes domésticos, retirada e queima de vegetação ciliar.

- A remoção da mata ciliar e da cobertura vegetal que as áreas da represa vêm sofrendo ao longo do tempo, tem causado impactos na qualidade hídrica do sistema. Isso torna os ambientes mais vulneráveis aos impactos da água de chuva, permitindo maior escoamento superficial de materiais para a água. Isso ficou bem evidenciado nos parâmetros: $\mathrm{pH}$, turbidez e sólidos totais, que sofreram variação sazonal bem significativa.

- Os afluentes demonstraram maior sensibilidade e vulnerabilidade em relação ao impacto das águas pluviais, se comparados ao reservatório.

- Os pontos próximos às zonas fluvial e lacustre são os mais impactados da represa, apresentando predominância do IQA médio. O ponto próximo à zona intermediária apresentou águas de melhor qualidade, com IQA bom.

- O sistema afluentes e represa apresentou característica dominante de estado "mesotrófico" para os pontos amostrais estudados.

Este trabalho evidenciou que é preciso adotar medidas mitigadoras visando à redução e controle do aporte de carga orgânica, nutrientes e sedimentos para a água, bem como a contenção do assoreamento, erosão e eutrofização dos corpos hídricos. Disciplinar e fiscalizar com mais rigor o uso e a ocupação do solo da região estudada também é uma das importantes tarefas que devem ser promovidas para a sua preservação. É necessário também dar prosseguimento aos estudos aqui apresentados para continuar avaliando a qualidade hídrica e o estado trófico do principal sistema de abastecimento de água de Juiz de Fora.

Espera-se que este trabalho seja útil para possibilitar a elaboração e execução de um plano de gestão integrada para a represa Dr. João Penido, conforme prevê a Política Nacional dos Recursos Hídricos (Brasil, 1997). Cabe destacar a importância da participação de todos os atores envolvidos, unificados dentro do conceito de gerenciamento ambiental da bacia (Pinder, 2013; Thornton et al., 2013a; 2013b).

Embora a natureza tenha maneiras para acomodar as perturbações e stress sofridos, a determinação da saúde dos ambientes lacustres é uma construção completamente humana (Thornton et al., 2013a). Portanto, constitui tarefa imprescindível das autoridades e responsabilidade de todos na preservação dos recursos hídricos, para que se possa garantir água de boa qualidade para os atuais e futuros usuários.

\section{AGRADECIMENTOS}

Os autores agradecem ao CNPq pelo auxílio financeiro, e à Quarta Companhia de Polícia Militar Independente de Meio Ambiente e Trânsito ( $4^{\text {a }}$ Cia PM Ind MAT) de Juiz de Fora, pelo auxílio na coleta das amostras.

\section{REFERÊNCIAS}

AMERICAN PUBLIC HEALTH ASSOCIATION (APHA). Standard methods for the examination of water and wastewater. 20th ed. Washington, 1998. 
ASSOCIAÇÃO BRASILEIRA DE NORMAS E TÉCNICAS (ABNT). NBR 9898. Preservação e técnicas de amostragem de efluentes líquidos e corpos receptores. Rio de Janeiro, 1987.

BRASIL. Lei $\mathbf{n}^{\mathbf{0}}$ 9.433, de 8 de janeiro de 1997. Disponível em: <http://www.planalto. gov.br/ccivil_03/Leis/L9433.htm>. Acesso em: 13 fev. 2011.

BRASIL. Ministério do Meio Ambiente. Conselho Nacional de Meio Ambiente (CONAMA). Resolução no 357, de 17 de março de 2005. Disponível em: <http://www.mma. gov.br/port/conama/legiano1.cfm?codlegitipo=3\&ano=2005>. Acesso em: 28 fev. 2010.

BRITO, S. L.; MAIA-BARBOSA, P. M.; PINTO-COELHO, R. M. Zooplankton as an indicator of trophic conditions in two large reservoirs in Brazil. Lakes \& Reservois: Research \& Management, v. 16, p. 253-264, 2011. http://dx.doi.org/10.1111/j.14401770.2011.00484.x

CARLSON, R. E. A trophic state index for lakes. Limmology and Oceanography, v. 22, n. 2, p. 361-369, 1977.

CARNEIRO, C.; PEGORINI, E. S.; ANDREOLI, C. V. Introdução. In: ANDRREOLI, C. V. Gestão integrada de mananciais de abastecimento eutrofizados. Curitiba: Finep, 2005. p. 25-44.

CARVALHO, A. R.; SCHLITTLER, F. H. M.; TORNISIELO, V. L. Relações da atividade agropecuária com parâmetros físicos químicos da água. Química Nova, v. 23, n. 5, p. 618-622, 2000. http://dx.doi.org/10.1590/S0100-40422000000500009

COMPANHIA AMBIENTAL DO ESTADO DE SÃO PAULO (CETESB). Água, rios e reservatórios: variáveis de qualidade das águas. São Paulo, 2010. Disponível em: <http://www.cetesb.sp.gov.br/Agua/rios/variaveis.asp\#cor>. Acesso em: 20 fev. 2010.

COMPANHIA DE SANEAMENTO MUNICIPAL (CESAMA) (Juiz de Fora). Mananciais. Represa Dr. João Penido. Disponível em: <http://www.cesama.com.br〉. Acesso em: 07 fev. 2010.

CUNHA, D. G. F.; CALIJURIA, M. C.; LAMPARELli, M. C. A trophic state index for tropical/subtropical reservoirs (TSItsr). Ecological Engineering, v. 60, p. 126-134, 2013.

CARMO M. S. do; BOAVENTURA G. R.; OLIVEIRA E. C. Geoquímica das águas da bacia hidrográfica do rio Descoberto, Brasília/ DF - Brasil. Química Nova, v. 28, n. 4, p. 565-574, 2005. http://dx.doi.org/10.1590/S0100-40422005000400002

DORES E. F. G. de C.; DE-LAMONICA-FREIRE E. M. Contaminação do ambiente aquático por pesticidas, estudo de caso: Águas usadas para consumo humano em Primavera do Leste, Mato Grosso - Análise preliminar. Química Nova, v. 24, n. 1, p. 27-36, 2001. http://dx.doi.org/10.1590/S0100-40422001000100007

ESTEVES F. de A. Fundamentos de limnologia. 2. ed. Rio de Janeiro: Interciência, 1998.

FERNANDES L. F.; LAGOS, P. D.; WOSIACK A. C.; PACHECO C. V.; DOMINGUES L.; ZENDER-ALVES L. et al. Comunidades fitoplanctônicas em ambientes lênticos. In: ANDREOLI, C. V.; CARNEIRO, C. Gestão integrada de mananciais de abastecimento eutrofizados. Curitiba: Finep, 2005. p. 303-366.

FORD D. E. Reservoir transport processes. In: Thornton, K. W. et al. Reservoir limnology: ecological perspectives. New York: John Wiley \& Sons, 1990. p. 15-41. 
HADDAD E. A. Influência antrópica na qualidade da água da Bacia Hidrográfica do Rio São Miguel, Carste do Alto São Francisco, Minas Gerais. 2007. 156 f. Dissertação (Mestrado em Geografia) - Universidade Federal de Minas Gerais, Belo Horizonte, 2007.

INSTITUTO MINEIRO DE GESTÃO DAS ÁGUAS - IGAM. Monitoramento da qualidade das águas superficiais no estado de Minas Gerais. Relatório Trimestral $1^{\circ}$ trimestre de 2010. Belo Horizonte, 2010. Disponível em: <http://www.igam.mg.gov. br/images/stories/qualidade/relatorio-trimestra-1-trim-2010.pdf.>. Acesso em: 15 jun. 2010 .

JUIZ DE FORA. Prefeitura. Juiz de Fora sempre. Plano Diretor de Desenvolvimento Urbano. Juiz de Fora: Funalfa Edições, 2004.

JUIZ DE FORA. Prefeitura. Secretaria de Planejamento e Desenvolvimento Econômico (SPDE). Ortofoto. Juiz de Fora, 2007.

KIMMEL, B. L.; LIND, O. T.; PAULSON, L. J. Reservoir primary production. In: THORNTON, K. W. et al. Reservoir limnology: ecological perspectives. New York: John Wiley \& Sons, 1990. p. 133-193.

LAMPARELli M. C. Graus de trofia em corpos d'água do estado de São Paulo: avaliação dos métodos de monitoramento. 2004. 238 f. Tese (Doutorado em Ciências na Área de Ecossistemas Terrestres e Aquáticos) - Universidade de São Paulo, São Paulo, 2004.

LEME ENGENHARIA S.A. Plano diretor de abastecimento de água da área urbana de Juiz de Fora. Recursos hídricos. v. IV/IX. Juiz de Fora: Prefeitura Municipal de Juiz de Fora, 1985.

LIU, Y.; WANG, Y.; SHENG, H.; DONG, F.; ZOU, R.; ZHAO, L. et al. Quantitative evaluation of lake eutrophication responses under alternative water diversion scenarios: a water quality modeling based statistical analysis approach. Science of the Total Environment, v. 468-469, p. 219-227, 2014. http://dx.doi.org/10.1016/j.scitotenv .2013 .08 .054

MINAS GERAIS. Conselho Estadual de Política Ambiental (COPAM). Deliberação Normativa no 16, de 24 de setembro de 1996. Disponível em: <http://www.siam.mg. gov.br/sla/download.pdf?idNorma=113>. Acesso em: 28 fev. 2010.

MINAS GERAIS. Secretaria de Estado do Meio Ambiente e Desenvolvimento Sustentável de Minas Gerais (SEMAD). Sistema de cálculo da qualidade da água (SCQA): estabelecimento das equações do índice de qualidade das águas (IQA). Relatório 1, 2005. Belo Horizonte: SEMAD, 2005. Disponível em: <http://www.engenharia ambiental.unir.br/admin/prof/arq/calculo-IQA.pdf>. Acesso em: 10 set. 2009.

PAGIORO T. A.; ROBERTO M. DO C.; THOMAZ S. M., PIERINI S. A.; TAKA M. Zonação longitudinal das variáveis limnológicas abióticas em reservatórios. In: RODRIGUES, L. (Org.). Biocenose em reservatórios: padrões espaciais e temporais. São Carlos: RiMa, 2005. p. 39-46.

PIMENTA, A. M.; ALBERTONI, E. F.; PALMA-SILVA, C. Characterization of water quality in a small hydropower plant reservoir in southern Brazil. Lakes \& Reservoirs: Research \& Management, v. 17, p. 243-251, 2012. http://dx.doi. org/10.1111/lre.12007 
PINDER, J. R. Lakes, landscapes and locals: pooling partnership resources to create sustainable lake catchments. Lakes \& Reservoirs: Research \& Management, v. 18, p. 15-25, 2013. http://dx.doi.org/10.1111//re.12016

RANGEL, L. M; SILVA, L. H. S.; ROSA, P.; ROLAND, F.; HUSZCAR, V. L. M. Phytoplankton biomass is mainly controlled by hydrology and phosphorus concentrations in tropical hydroelectric reservoirs. Hydrobiologia, v. 693, n. 1, p.13 - 28, 2012. http://dx.doi.org/10.1007/s10750-012-1083-3

SILVA, A. P. de S.; DIAS, H. C. T.; BASTOS, R. K. X.; SILVA, E. Qualidade da água do reservatório da Usina Hidrelétrica (UHE) de Peti, Minas Gerais. Revista Árvore, Viçosa, v. 33, n. 6, p. 1063-1069, 2009. http://dx.doi.org/10.1590/S0100-67622009000600009

SILVA, N. da; NETO, R. C.; JUNQUEIRA, V. C. A.; SILVEIRA, N. F. de A. Manual de métodos de análise microbiológica da água. São Paulo: Varela, 2005.

SOARES, M. C. S.; MARINHO, M. M.; HUSZAR, V. L. M.; BRANCO, C. W. C.; AZEVEDO, S. M. F. O. The effects of water retention time and watershed features on the limnology of two tropical reservoirs in Brazil. Lakes \& Reservoirs: Research \& Management, v. 13, p. 257-269, 2008. http://dx.doi.org/10.1111/j.1440-1770. 2008.00379.x

STANTON, A. G. Primer of biostatistics - Version 4.0. $4^{\text {th }}$ ed. New York: McGraw Hill, 1997.

THORNTON, J. A.; LIN, H.; SLAWSKI, T. M. People and ponds: the participatory role of humans in Integrated Lake Basin Management. Lakes \& Reservoirs: Research \& Management, v. 18, p. 3-4, 2013a. http://dx.doi.org/10.1111//re.12020

THORNTON, J. A.; SLAWSKI, T. M.; OLSON, E. Protecting in partnership: the Mukwonago River Basin Protection Plan. Lakes \& Reservoirs: Research \& Management, v. 18, p. 67-80, 2013b. http://dx.doi.org/10.1111//re.12021

THORNTON, K. W. Sedimentary process. In: THORNTON, K. W. et al. Reservoir limnology: ecological perspectives. New York: John Wiley \& Sons, 1990. p. 43-69.

VIEIRA, S. Análise de variância (ANOVA). São Paulo: Atlas, 2006.

VON SPERLING, E. Morfologia de lagos e represas. Belo Horizonte: Departamento de Engenharia Sanitária e Ambiental da Universidade Federal de Minas Gerais (DESA/UFMG), 1999.

\section{ERRATA}

Revista Ambiente \& Água, Taubaté, v.9 n.1, jan. - mar. 2014

doi: 10.4136/ambi-agua.1438

BUCCI, Magaly H. S.; OLIVEIRA, Luiz Fernando C. de. Índices de Qualidade da Água e de Estado Trófico na Represa Dr. João Penido (Juiz de Fora, MG). Rev. Ambient. Água, Taubaté, v. 9, n. 1, Mar. 2014. Available from <http://www.scielo.br/scielo.php?script=sci_arttext\&pid=S1980-993X2014000100013\&lng=en\&nrm=iso>. http://dx.doi.org/10.4136/ambi-agua.1290.

1) página 135: onde se lê: "PT: - concentração de fósforo total ...", leia-se: PT: concentração de fósforo total ...;

2) página 143: onde se lê: "O ponto PR2 difere estatisticamente dos pontos 1 e 2, ...", leia-se: "O ponto PR2 difere estatisticamente dos pontos PR1 e PR3, ...”. 